\title{
Enterprises as the main body to promote "The Belt and Road" international cooperation
}

\author{
Lili Chen* \\ School of Management \\ Shanghai University of Engineering Science \\ Shanghai,China \\ 1094873944@qq.com
}

\author{
$\mathrm{Bin} \mathrm{Hu}$ \\ School of Management \\ Shanghai University of Engineering Science \\ Shanghai,China \\ hubinlyj@163.com
}

\begin{abstract}
With economic globalization going on and the economy emerging as a new norm, international cooperation is becoming increasingly frequent. The development of Chinese enterprises are faced with a complex situation. "The Belt and Road" provides a bridge for international cooperation, but also provides significant opportunities for the development of enterprises in our country. This paper aims at the problems of international cooperation of Chinese enterprises and puts forward how to promote the enterprise as the main body to advance "The Belt and Road" international cooperation and development strategy.
\end{abstract}

Keywords-The Belt and Road; enterprise; international cooperation

\section{INTRODUCTION}

"The Belt and Road" rooted in the ancient Silk Road, which refers to the economic belt of land Silk Road, and the general term for the maritime Silk Road in twenty-first Century. General Secretary $\mathrm{Xi}$ Jinping put forward the initiative in 2013, a new thinking and new ideas adopted in order to cope with the change of international pattern. "The Belt and Road" strategy brings the opportunities, markets and resources to Chinese enterprises and creates a good environment for the development of international cooperation. Therefore, to deepen international cooperation and to play the main role of enterprises and their own advantages will promote international cooperation of enterprises to a new height.

\section{THE MAIN BODY OF ENTERPRISES IN “THE BELT AND ROAD"}

"The Belt and Road" is both an opportunity and a challenge. In this process, whether state-owned or private Chinese enterprises, they both can realize the ambition. Chinese enterprises can constantly display their talent and innovation and constantly introduce talents and use talents. The enterprise is not only a market carrier of economic cooperation with foreign countries, but also the main body of "The Belt and Road". The government should give more support to enterprises and encourage enterprises to act as a pioneer of "The Belt and Road". First of all, the number of overseas enterprises is huge. As the main body of "The Belt and Road", in 2016 our country has more than 30,000 overseas enterprises, the total assets amounted to $\$ 6.4$ trillion. With the arrival of "The Belt and Road", the number of Chinese overseas enterprises is growing, which plays a main role for promoting the development of "The Belt and Road". Secondly, the enterprise is the main body of innovation. The enterprise is an important force for the combination of science and economy, so they should become the main body of technological innovation, R\&D investment, scientific research organization and achievement transformation. Under new economic norm, scientific and technological innovation is absolutely necessary. It's important for enterprise to strengthen the dominant position and leading role of innovation and support the healthy development of small and medium-sized scientific and technological enterprises, in order to form a batch of internationally competitive and innovative leading enterprises and to promote the long-term development of "The Belt and Road". Finally, enterprises are the main body of the introduction, training and use of talents. "The Belt and Road" provided a platform for the introduction and use of talents for our country and became a choice of releasing talent bonus for more and more enterprises .

\section{III. “THE BELT AND ROAD” BRINGS OPPORTUNITIES TO} CHINESE ENTERPRISES OF INTERNATIONAL COOPERATION

\section{A. Provide a new basis for enterprises to effectively integrate resources}

The countries along "The Belt and Road" have rich resources and energy advantages that some of them in our country are deficient. At the same time, our country can also provide some resources and energy to the countries along "The Belt and Road", and provide the foundation for Chinese enterprises to effectively integrate resources. The countries along "The Belt and Road" have abundant resources and favorable metallogenic conditions, but they lack the ability of exploration and development. So it has great potential for resource development, which is in line with the advantages of Chinese enterprises in the development of resources and market transactions. "The Belt and Road" is an actual need for the development of central and western regions and Eastern transformation, also the opportunities for the attention and cultivation of human resources. The development of "The Belt and Road" cannot live without the support of talent. In the background of the rapid development of economy, enterprises should change the mode of thinking, using new tools and technology to manage talents, to cultivate talents and to use talents. Actively deepening international cooperation,

\footnotetext{
*Corresponding author
} 
effectively introducing talents, retaining talents, developing talents and improving the utilization rate of resources can boost the enterprise quickly into the international market.

\section{B. Provide new opportunities for enterprises to enhance their competitiveness}

The main role of enterprises in economic development has become more and more obvious. The competitiveness is the essential factor of survival and development of enterprises. The countries along "The Belt and Road" are some developing countries, having a broad emerging market and a great market potential. Economic globalization has accelerated the use of domestic and international markets in the world. Actively carrying out international cooperation and striving for their status in the international development contribute to help Chinese enterprises to use worldwide resources, such as human resources, material resources and technical resources, to enhance their own strength, and enhance their own competitiveness. "The Belt and Road" brought many opportunities for enterprises, broadened the enterprise market and strengthened development space, but it also means that external competition is becoming increasingly fierce. The unsafe factors of the international market still exists, so when enterprises face the opportunities of "The Belt and Road", they also should face the challenge to "The Belt and Road". Timely developing and transforming and improving core competitiveness can better integrate into the trend of international economy.

\section{Provide new directions for enterprises to solve their overcapacity}

At present, the overcapacity of enterprises has existed on the Chinese market, which seriously affecting the economy. It's the serious problem that Chinese enterprises need to solve quickly [1]. China's export mode is traditional with single exporting country. The capacity of development has reached the limit state. Excess capacity can not be solved. Many countries along "The Belt and Road" are less developed, and many of their enterprises need to be developed. Transferring the excess capacity of our enterprise to these overseas enterprises can develop new markets for Chinese enterprises and can be complementary with their resources. It not only helps these countries develop enterprises, but also helps enterprises improve the problem of overcapacity in China.

\section{THE PROBLEMS OF CHINESE ENTERPRISES IN INTERNATIONAL COOPERATION}

\section{A. Enterprise innovation capability needs to be strengthened}

According to the global innovation index report 2016 that the global innovation index in the top 5 countries is Switzerland, Sweden, Britain, the United States and Finland. Singapore ranked sixth, South Korea ranked eleventh, Japan ranked sixteenth. China, for the first time among the top 25, ranked 14th, which compared to the previous year rose 4 ranking [2]. However, the innovation ability of Chinese enterprises is not optimistic. Innovation ability should be strengthened. Innovation is the key to promote the long-term economic development. With the economic globalization, the development of economic in various countries has entered a critical period. Chinese enterprises should seize the opportunities of "The Belt and Road", constantly enhance their innovation ability and improve their competitiveness, to go farther and farther on the road of economic development.

\section{B. The service system of international cooperation is not perfect enough}

In recent years, with continuously deepening international cooperation, China has formed a cooperative system on ceeusro that government to led, enterprises to participate in and R\&D institutions to communicate. It shows the full range of international cooperation situation. Enterprises need a service system to support international cooperation. Government should actively encourage enterprises to "go out", at the same time, it should provide the perfect service system as a guarantee of the enterprises. But in fact, the service system of international cooperation in Chinese enterprises is not perfect, and to a certain extent it restricts the cooperation with foreign enterprises. Firstly, China has a lot of service institutions, but the price of the service is expensive, some small and medium-sized enterprises cannot afford. So enterprises can't obtain relevant information, which leads to lose business opportunities for international cooperation. Secondly, lacking perfect protection services of rights. Chinese enterprises need to improve the protection mechanism of rights to be the shield and buckler, which can ensure the guarantee of enterprises' legal rights in overseas. At present, the lack of overseas protection institutions of rights has led to the rights of many companies being not guaranteed and maintained. The interests of enterprises have been damaged. Finally, it suppresses the cooperation enthusiasm for enterprises "going out" .

\section{Enterprises as the MaIn Body to Promote the STRATEGY OF “THE BELT AND ROAD” INTERNATIONAL COOPERATION}

\section{A. Enhance the capability of independent innovation of our enterprises}

Innovation ability is the key factor for enterprise's survival and development. Actively playing the main role of the enterprise and establishing the integration of ceeusro technological innovation system can promote international cooperation in science and technology and enhance the independent innovation capability of our enterprises. China need a good product R\&D system and foster innovative technological enterprises to actively integrate the resources of enterprises, universities and scientific research institutions and to vigorously develop high-tech enterprises. Chinese enterprises should pay attention to the innovation of science and technology, make full use of foreign advantages and effectively integrate domestic and foreign advanced and innovative resources, in order to enhance the enterprises' core technology and accelerate the growth of the enterprise. It's important to increase the support for enterprises' technological innovation in order to support Chinese enterprises "going out" and establish R\&D institutions in the more developed region. Helping companies develop new products, establishing innovative management mode and actively exploring the market can enhance innovation capability and core competitiveness and narrow the technology level of Chinese enterprises with the international advanced enterprises. Combined with the "Internet + " technology, enterprises should 
improve the mode of production and optimize the mode of management, in order to achieve enterprises' information and networking [3].

\section{B. Construct a perfect service system with enterprise as the main body}

The establishment of perfect overseas investment guarantee system can ensure that all aspects of interests of "going out" enterprises. Combined with China's national conditions, the government can learn from the successful experience to establish a relevant security system. Signing trade agreements and treaties with overseas cooperative countries can ensure the balance of interests of both sides, while ensuring that Chinese enterprise's investment security in overseas. The government should improve the incentive mechanism to encourage enterprises to strengthen international cooperation and to "go out" bravely. Establishing overseas service platforms of enterprises as the main body can actively publish information services related to the foreign market for enterprises. So enterprises can grasp the first time information and acquire the opportunities of international cooperation by using information. Good overseas protection system of investment rights can actively publicize laws and regulations knowledge to overseas enterprises, improve enterprises' rights awareness, broaden the channels of enterprises' rights protection and protect the rights of overseas enterprises,finally strengthen the enthusiasm for enterprise "going out".

\section{Rely on international cooperation to enhance the competitiveness of Chinese enterprises}

According to the global competitiveness report 2016-2017 data, the top ten are Switzerland, Singapore, the United States, Holland, Germany, Sweden, Britain, Japan, Hongkong China, Finland [4]. China Hongkong's rank compared to last year has declined. But China ranked twenty-eighth, which has increased compared to previous year. But the competitiveness of enterprises in China still need to be strengthened. Enterprises should strengthen international cooperation, actively introduce foreign enterprises with advanced technology, strengthen domestic and foreign enterprises to cooperation in technology, absorb foreign advanced technology and strengthen technological innovation of Chinese enterprises [5]. At same time, it's important for enterprises to adjust the structure of Chinese enterprises' production, to cultivate the independent brand of the enterprise, to try to move closer to internationalization and improve the international competitiveness of enterprises. In fact, the competitiveness of enterprises is the competition of talents. So it is important to cultivate talents' competitiveness and lay a solid foundation for enterprises in order to improve their international competitiveness [6].

\section{CONCLUSION}

In summary, the propose of "The Belt and Road" strategy provides many opportunities for the long-term development of Chinese enterprises and economy, but also has laid a solid foundation for Chinese enterprises to embark on the road of international cooperation. Therefore, Chinese enterprises should grasp the opportunity to deepen international cooperation, actively play its dominant position, improve service system and enhance innovation capacity and competitiveness in order to better integrate into the international cooperation in the trend.

\section{ACKNOWLEDGMENT}

For this paper, first of all, I would like to thank my tutor, Professor Hu Bin, for his careful guidance and help. He gives me a great encouragement. From the guidance of the thesis writing to the accomplishment of the paper, it embodies the teacher's selfless care and expectation. Of course, I'd like to thank to other experts, scholars in the academic too. They offer inspiration for me. Of course there are many defects in my paper, I hope to be perfect through further research in the future study and work.

\section{REFERENCES}

[1] Y. Zhao, "Opportunities and challenges of "The Belt and Road" bring to the "go Out" enterprises. Business," vol. 35, 2015, p. 167.

[2] The Global Innovation Index 2016, 2016.

[3] B. Pan, "High-tech enterprises as the main body to promote "The Belt and Road" international cooperation in science and technology," Enterprise Reform and Management, vol. 23, 2016, pp. 198-199.

[4] The Global Competitiveness Report 2016-2017, 2016.

[5] G.S. Wang, "How to enhance the core competitiveness of enterprises under "The Belt and Road" idea," Enterprise Reform and Management, vol. 12, 2016, p. 5.

[6] L.L. Wang, "The Belt and Road" talent development new opportunities Human Resource Management, vol. 3, 2016, pp. 6-7. 